\title{
VIRTUAL TEST OF FIRE RESISTANCE OF A STEEL BEAM
}

\author{
K. Cábová*, N. Lišková ${ }^{* *}$, F. Zeman ${ }^{* * *}$, M. Benýšek ${ }^{\dagger}$
}

\begin{abstract}
The paper describes a virtual fire-resistance tests which forms the first part of a coupled numerical model for prediction the fire resistance of elements in a horizontal furnace. The temperature model takes advantage of great possibilities of computational fluid dynamics code Fire Dynamics Simulator. The model is based on an accurate representation of a real fire furnace of fire laboratory PAVUS a.s. located in the Czech Republic. It includes geometry of the real furnace, material properties of the furnace linings, burners, ventilation conditions and also a tested specimen with measurement devices. The model allows controlling of gas temperature and the static over pressure in the volume of the furnace as it is specified in requirements of European standard for fire resistance tests. The paper presents several improvements of the model which lie in an accurate description of physical material properties, usage of a finer mesh density and application of a forced ventilation system. The improved virtual furnace is used to calculate temperature environment around a steel beam. The temperature fields are then passed to thermomechanical model to solve mechanical behavior of the tested element.
\end{abstract}

Keywords: fire-resistance test, numerical model, virtual furnace, FDS, steel beam

\section{Introduction}

Testing by standard fire test is the common method of obtaining fire-resistance rating of structural elements, see (Buchanan, 2001). Despite fire-resistance tests are very common, they can be quite time consuming regarding their planning, preparation, and analysis of results of the test. The cost of the test is also very high. Because of these drawbacks, a coupled numerical model to predict fire resistance of a steel beam in a horizontal furnace is developed. This paper deals with the part of fluid dynamics which objective is to solve the temperature environment inside the furnace. The numerical model of the furnace introduced in (Cabova et al., 2017) is improved to be used for calculation of fire resistance of a steel beam.

The improvement of the model lies in accurate description of physical material properties, usage of a finer mesh density and application of a forced ventilation system.

After validation of the temperature model in Fire Dynamics Simulator (FDS), the temperature conditions are passed to the thermo-mechanical model which solves heat transfer and mechanical behaviour of the tested element. The thermo-mechanical part of the coupled model solved in OOFEM is presented in (Šulc, 2017).

\footnotetext{
Ing. Kamila Cábová, PhD.: Department of Steel and Timber Structures, Faculty of Civil Engineering, Czech Technical University in Prague, Thákurova 7; 166 29, Prague; CZ, kamila.cabova@fsv.cvut.cz

** Ing. Nikola Lišková: Department of Steel and Timber Structures, Faculty of Civil Engineering, Czech Technical University in Prague, Thákurova 7; 166 29, Prague; CZ, nikola.liskova@fsv.cvut.cz

*** Bc. Filip Zeman: Faculty of Civil Engineering, Czech Technical University in Prague, Thákurova 7; 166 29, Prague; CZ, filip.zeman@fsv.cvut.cz

$\dagger \quad$ Ing. Martin Benýšek: Department of Concrete Structures, Faculty of Civil Engineering, Czech Technical University in Prague, Thákurova 7; 166 29, Prague; CZ, martin.benysek@fsv.cvut.cz
} 


\section{Model of the furnace with a steel beam}

\subsection{Description}

The model is created in the computational fluid dynamics code FDS (Fire Dynamics Simulator) version 6.5.4 (McGrattan et al., 2014). Geometry of the furnace, material properties of furnace linings, burners and ventilation conditions are created to correspond to the horizontal furnace of fire laboratory PAVUS a.s. described in (Cabova et al., 2017). A steel beam IPE 400 is placed below the ceiling of the model and fitted with devices to calculate its inside temperature and adiabatic surface temperature.

The model consists of two computational meshes. Size of the general mesh M1 is $125 \mathrm{~mm} \times 125 \mathrm{~mm} \times$ $125 \mathrm{~mm}$. In the region around the beam the mesh is refined to $62 \mathrm{~mm} \times 62 \mathrm{~mm} \times 62 \mathrm{~mm}$ (mesh M2). In the bottom part of the model the mesh is enlarged to simulate the conduit of the gas exhaust system. The door of dimensions $0.5 \mathrm{~m} \times 1.75 \mathrm{~m}$ and four visors are simulated in the computational model as can be seen in Fig. 1. Red squares in the figure show locations of eight burners. Visualization of the virtual furnace with the beam (left) and two computational meshes of the model (right) are shown in Fig. 1.
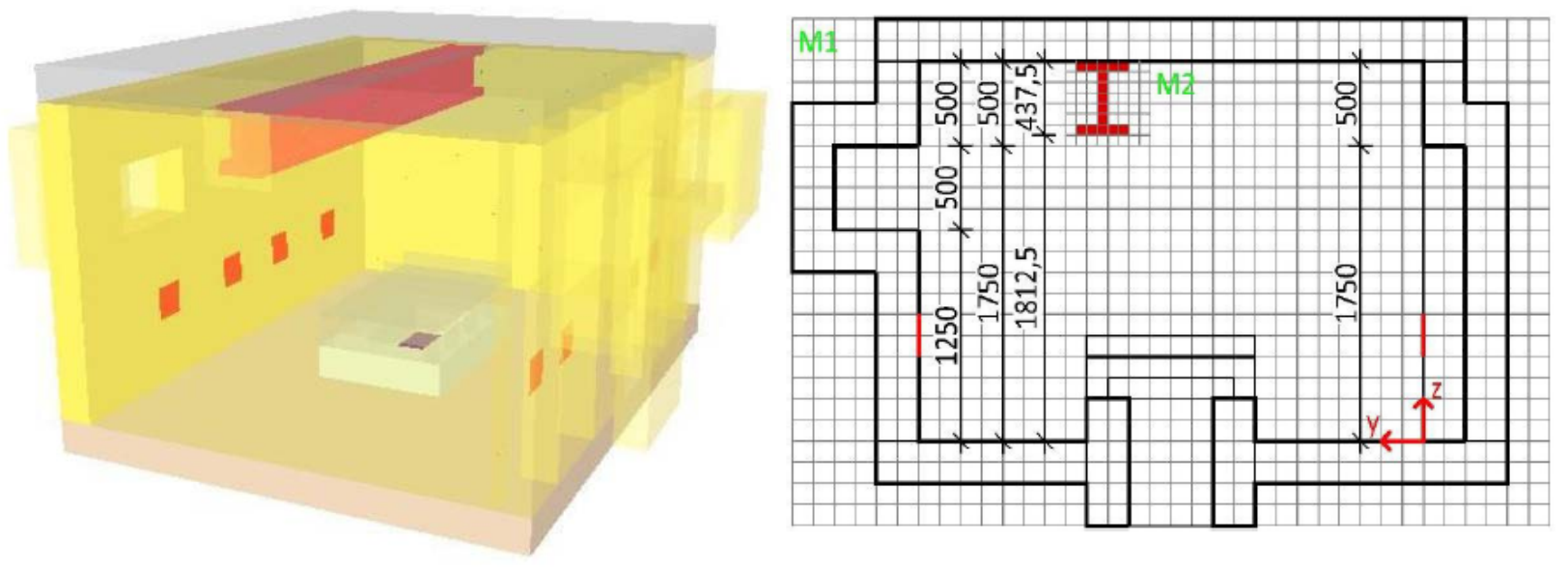

Fig. 1: Model of the furnace with steel beam (left); Computational meshes of the model (right).

Material properties of the furnace linings are mainly taken from data sheets of manufacturers as it is presented in (Cabova et al., 2017). An improvement of the current model lies in new material properties. Some of them come from our own material testing. For example a temperature dependant curve of thermal conductivity of refractory ceramic fibres is shown in Fig. 2. Thermal conductivity of high alumina bricks, thermally insulating bricks, calcium silicate boards, blocks of refractory ceramic fibres, steel and insulating refractory concrete is set as a temperature dependent value. Specific heat capacity of high alumina bricks, thermally insulating bricks and steel is set also as temperature dependent value. Other values of specific heat capacity and density are set as constant values.

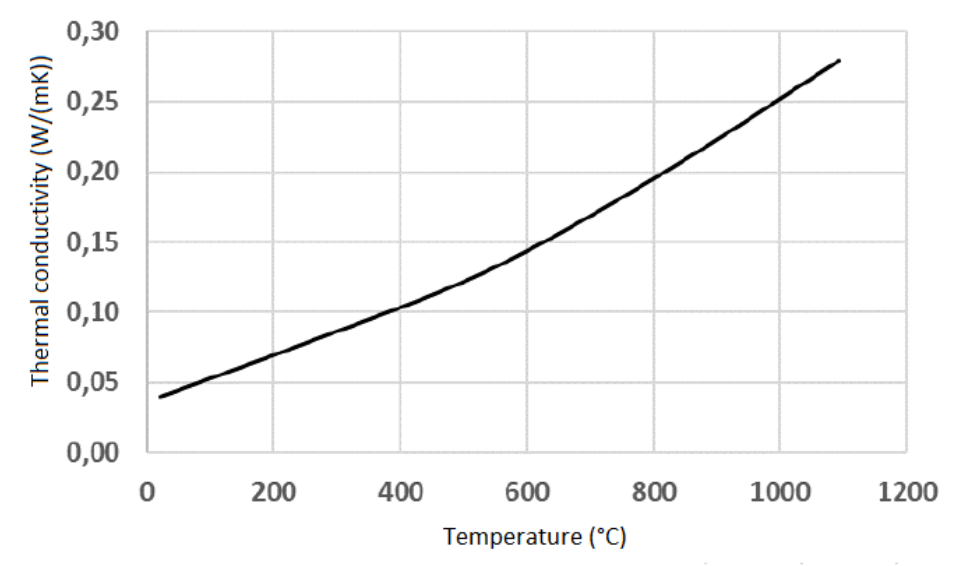

Fig. 2: Thermal conductivity of refractory ceramic fibres.

In the model burners are simulated as eight square surfaces of type VENT of dimension $250 \mathrm{~mm} \times 250$ $\mathrm{mm}$, which are located $0.5 \mathrm{~m}$ above the floor. The fuel in the virtual furnace is composed of the mixture 
of natural gas and air, as it is in the case of real furnace. Power of the burners in the model is gradually increased in dependence on time according to the power of burners measured in a fire test. In the model it is defined by a ramp function of heat release rate per surface area (HRRPUA) with the maximal value of $4249.12 \mathrm{~kW} / \mathrm{m}^{2}$. Mass flow of each burner follows the same ramp function as it is defined for the power. Maximal value of the mass flow of the burner is set to $2.0 \mathrm{~kg} /\left(\mathrm{m}^{2} \mathrm{~s}\right)$.

Ventilation system is the next improvement of the model. The ventilation is ensured by an opening of dimensions $0.6 \mathrm{~m} \times 0,8 \mathrm{~m}$ in the floor leading to a duct to the border of the computational domain. At the end of the duct there is a fan of the maximal power $4.0 \mathrm{~m}^{3} / \mathrm{s}$. The power of the fan is regulated by the pressure device which is located inside the furnace. Inside over pressure should be within the limits given in EN 1363 - 1.

In the model gas temperature is calculated by device type THERMOCOUPLE. Properties of the device are modified in the model to correspond to properties of coated thermocouple used in the validation fire test. Then, device type ADIABATIC SURFACE TEMPERATURE is used in the model to simulate a weighted average value of the radiation temperature and the gas temperature. The name of this weighted average became known as adiabatic surface temperature (AST) (Wickström, 2016). Gas static over pressure inside the volume of the virtual furnace is also calculated.

\subsection{Results and validation}

For standard fire testing it is important to meet requirements of standard EN 1363-1:2013, which defines the conditions of fire resistance tests. Two constraints (gas temperature and gas static over pressure) must be achieved in the real furnace as well as in the model. With the purpose to check the requirements given in EN 1363 - 1 the gas temperature and the gas static over pressure evolution in time are presented in Fig. 3. The development of temperature from the model is compared with the standard temperature-time curve and with the curve measured during the fire test. In the figure there are also two curves showing the upper and the lower tolerance according to EN 1363 - 1. Based on the diagram it may be stated that after 5 min the gas temperature is within the acceptable tolerance given in EN 1363 - 1. The level of the gas static over pressure in the model with the steel beam ranges mainly between $15 \mathrm{~Pa}$ and $25 \mathrm{~Pa}$, which is about $5 \mathrm{~Pa}$ higher than recommended by EN 1363 - 1. There are some higher deflections between 15 min and $20 \mathrm{~min}$.
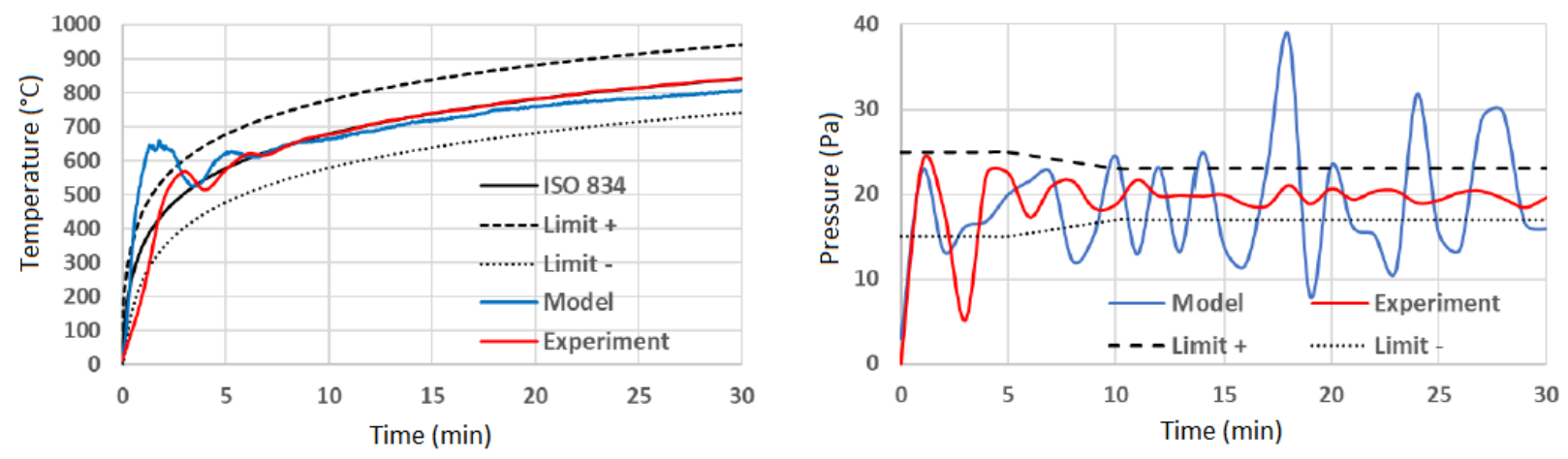

Fig. 3: Gas temperature development $100 \mathrm{~mm}$ below the ceiling in the model with a steel beam (left); Gas static over pressure in the model with a steel beam (right).

In the virtual furnace steel temperature was calculated by the device type INSIDE WALL TEMPERATURE located at the upper and lower flange and the web of the steel profile. All these devices were placed in the centre of thicknesses of all parts. Development of steel temperature in time of all parts is presented in Fig. 4 (left). Adiabatic surface temperature was calculated by placing the device ADIABATIC SURFACE TEMPERATURE on the surface of the upper and lower flange and the web of the steel profile. The evolution of the adiabatic surface temperature in time is shown in Fig. 4 (right). Although steel temperature of the lower flange calculated by both types of devices reach $800{ }^{\circ} \mathrm{C}$ in 30 min, the development in the initial 10 min differs considerably. The adiabatic surface temperature is sensitive to the radiative heat flux coming from burners and lining of the furnace, therefore it gives higher values in the initial phase comparing to inside steel temperature. 

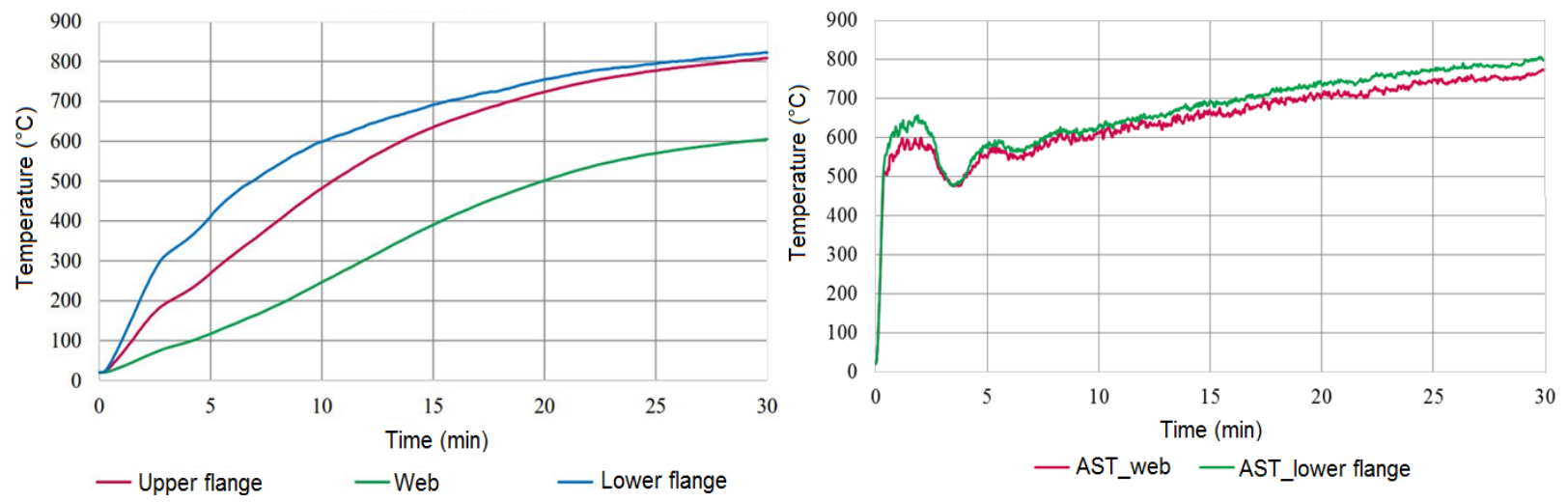

Fig. 4: Steel temperature calculated in the virtual furnace (left); Adiabatic surface temperature of the steel beam calculated in the virtual furnace (right).

\section{Conclusions}

The paper presents the improved model of the horizontal furnace for fire-resistance tests. The improvement of the numerical model calculated in CFD code FDS lies in the ventilation system. The system includes the fan which power is controlled by a pressure device. The forced ventilation helps to keep the pressure in required limits. Another point of the improvement lies in material properties of the linings of the furnace. Properties are mainly set as temperature dependant values. This improvement brings the virtual furnace closer to the real furnace. Finally, the mesh is finer comparing to previous model presented in (Cabova et al., 2017). With improved ventilation system, accurate material properties and finer mesh, more accurate results are achieved. Certainly, further development is needed to improve the model. Namely, to include an automatic system of burners which power can be controlled by adiabatic surface temperature calculated below the virtual furnace ceiling.

The virtual furnace presented in this paper allows to control gas temperature and the static over pressure in the volume of the furnace, so it can meet the requirements of European standard EN 1363-1:2013, which defines the conditions for fire resistance tests. The model is used to calculate temperature environment around the steel beam IPE400. After validation of the model, the temperature conditions are passed to the thermo-mechanical model which solves heat transfer and mechanical behaviour of the tested element. In conclusion, the virtual furnace has a great potential for investigating the thermal behaviour of fire-resistance tests. A huge advantage inheres in the evaluation of the thermal effect throughout the volume of the furnace, which allows an accurate prediction of fire-resistance tests and evaluation of large number of technical alternatives and boundary conditions. It may be also used for optimization of settings of the real furnace in order to reach as uniform temperature resolution across the volume of the furnace as possible.

Research presented in this paper was supported by project n. 16-18448S in the frame of Czech science foundation (GA CR).

\section{References}

Buchanan, A. H. (2001) Structural Design for Fire Safety. University of Canterbury, New Zealand.

Cabova, K., et al. (2017) Modelling of standard fire test, in: Engineering Mechanics 2017, Brno University of Technology, Brno, pp. 226-229.

McGrattan, K., et al. (2014) Fire Dynamics Simulator (Version 6) - User’s Guide. Gaithersburg, Maryland, USA: National Institute for Standards and Technology, Special Publication 1019 - Sixth Edition.

Šulc, S., Šmilauer, V. and Wald, F. (2017) Coupled simulation for fire-exposed structure using CFD and thermomechanical models, in: Engineering Mechanics 2017, Brno University of Technology, Brno, pp. 946-949.

Wickström, U. (2016) Temperature Calculation in Fire Safety Engineering. Springer International Publishing, Switzerland. 